\title{
DETECTION OF CHROMOSOMAL ABNORMALITIES OF CHROMOSOME 12 IN UTERINE LEIOMYOMA USING FLUORESCENCE IN SITU HYBRIDIZATION
}

\author{
Satoshi Hayashi, ${ }^{*}$ Norio Miharu, Etsuji OKamoto, \\ Osamu Samura, Tetsuaki Hara, and Koso OHama \\ Department of Obstetrics and Gynecology, Hiroshima University School of Medicine, \\ 1-2-3 Kasumi, Minami-ku, Hiroshima 734, Japan
}

Summary Fifty uterine leiomyomas were examined using conventional cytogenetic method and fluorescence in situ hybridization (FISH) for detection of chromosomal abnormalities of chromosome 12. Of the 50 tumors, nine were examined using FISH on the non-cultured samples. Two (4.0\%) of 50 tumor samples examined showed chromosomal abnormalities of chromosome 12 by the conventional cytogenetic analysis. For FISH, the whole-chromosome painting probe and D12Z3 probe specific for the centromeric region were used. Of the 50 cultured samples, 10 showed structural aberrations and four showed numerical aberrations of chromosome 12 by FISH analysis. Of the nine non-cultured samples, four showed structural abnormalities of chromosome 12, all of which also showed structural abnormalities of chromosome 12 on the cultured samples. These results indicate that chromosomal abnormalities of chromosome 12 are important in the biology of at least some types of uterine leiomyoma, and that FISH is a useful complement to the conventional cytogenetic analysis in the study of solid tumors.

Key Words fluorescence in situ hybridization (FISH), uterine leiomyoma, benign tumor, chromosome 12

\section{INTRODUCTION}

As a result of the development of the fluorescence in situ hybridization (FISH) technique in recent years, it has become possible to analyze chromosomal abnormalities in all phases of cell division, including interphase. FISH hence

Received September 11, 1995; Revised version accepted December 14, 1995.

* To whom correspondence should be addressed. 
appears to be useful for the detection of chromosomal abnormalities and is a convenient complement to conventional cytogenetic analysis, in particularly solid tumors which present technical obstacles to obtaining sufficient quantities of quality metaphases. This technique can be also applied to a variety of tumors, including hematologic disorders (Brizard et al., 1994).

Uterine leiomyoma are benign smooth muscle tumors in the female genital organs, whose size and growth are dependent on ovarian steroids (Fujii, 1992; John and Martin, 1971). Although their etiology has not yet been well fully known and characterized, in recent years, a large number of analyses in uterine leiomyoma have been performed and rearrangements of chromosome 12 have been found as one of the major chromosome aberrations. Similar rearrangements of chromosome 12 are also common in other benign tumors (Mark and Dahlenfors, 1986; Nilbert and Heim, 1990; Sreekantaiah et al., 1991; Sreekantaiah and Sandberg, 1991).

In the present study, we have investigated chromosome 12 aberrations by FISH on cultured and non-cultured cells and demonstrated the usefulness of FISH to detect chromosome aberrations in uterine leiomyoma which is solid tumor.

\section{MATERIALS AND METHODS}

Preparation of slides. Fifty uterine leiomyomas were obtained from 26 patients. All of them showed histological characteristics of leiomyoma. To obtain cultured cells for FISH and cytogenetic analysis, 50 tissue samples were processed according to the method of Limon et al. (1986). To obtain cell suspensions for non-cultured analysis with FISH, nine of 50 tissue samples were minced into small pieces and digested with collagenase $(300 \mathrm{U} / \mathrm{ml})$. Cultured and non-cultured cells were treated with $0.075 \mathrm{~mol} / \mathrm{liter} \mathrm{KCl}$ for $20 \mathrm{~min}$, and fixed with $3: 1$ methanol/ acetic acid fixative, and slides were made by dropping and air drying.

$D N A$ probes. Digoxigenin-labeled chromosome 12 alpha-satellite probe (D12Z3) was purchased from Oncor, Inc. (Gaithersburg, MD). Chromosome 12 whole-chromosome painting probe (WCP12) labeled with green fluorescent hapten (Spectrum Green, Imagenetics) was purchased from Imagenetics (Naperville, IL).

Fhorescence in situ hybridization (FISH). FISH was performed according to manufacture's instructions of Oncor, Inc. and Imagenetics with some modifications. Briefly, D12Z3 and WCP12 were used in combination and hybridization solution was denatured simultaneously with interphase nuclei slide at $85^{\circ} \mathrm{C}$. Those slides were placed to hybridize at $37^{\circ} \mathrm{C}$ in dark moist chambers overnight. After post washing, hybridization of D12Z3 was detected by rhodamine-conjugated antidigoxigenin IgG (Boehringer-Mannheim, Indianapolis, IN). Interphase nuclei were counterstained by 4,6,-diamidino-2-phenylindole (DAPI) and propidiumiodide (PI). 
A
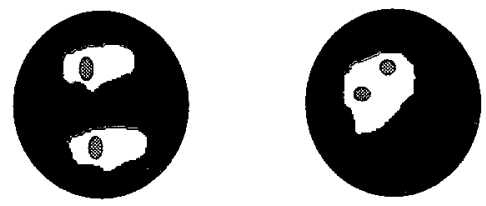

B

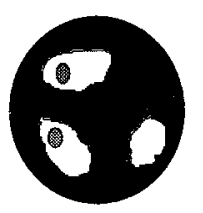

C

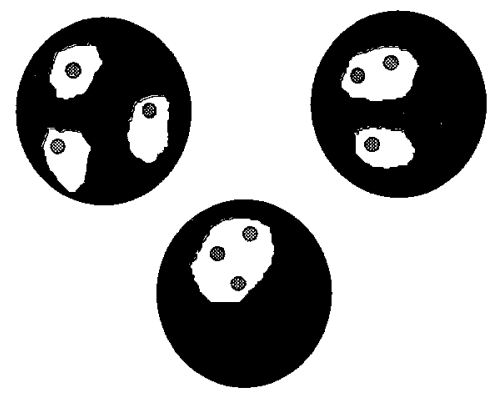

Fig. 1. Schematic representation of the regions of chromosome 12 identified by the whole-chromosome painting probe and the alpha-satellite probe. A: Nuclei with normal of chromosome 12. B: Nucleus with structural abnormality of chromosome 12. C: Nuclei with trisomy of chromosome 12 or nuclei of triploidy. Punctate alpha-satellite signals are generally observed as distinct domains whereas the more diffuse painting probes are frequently observed to have overlapping domains. $\square$ whole-chromosome painting probe, ․: alphasatellite probe, 4,6-diamidino-2-phenylindole and propidium-iodide.

Hybridization signals were observed in at least 200 nuclei for each specimen with an Optiphot microscope (Nikon, Inc., Tokyo, Japan). A triple-band pass filter for simultaneous observation of rhodamine, Spectrum Green, DAPI, and PI was utilized. Structural aberration of chromosome 12 was inferred when two WCP12 signals with D12Z3 signals and a WCP12 signal without D12Z3 signal were observed (Figs. 1 and 2). Numerical aberration was inferred when one, two, or three chromosome 12 painting signals with three D12Z3 signals were observed (Fig. 1).

Control study. Cultured and non-cultured cells of uterine myometriums which were karyotyped as $46, \mathrm{XX}$ were used for control study. FISH with more than 1,000 nuclei obtained from 5 different cultured myometriums, and with more than 400 nuclei from 2 different non-cultured myometriums were performed. 

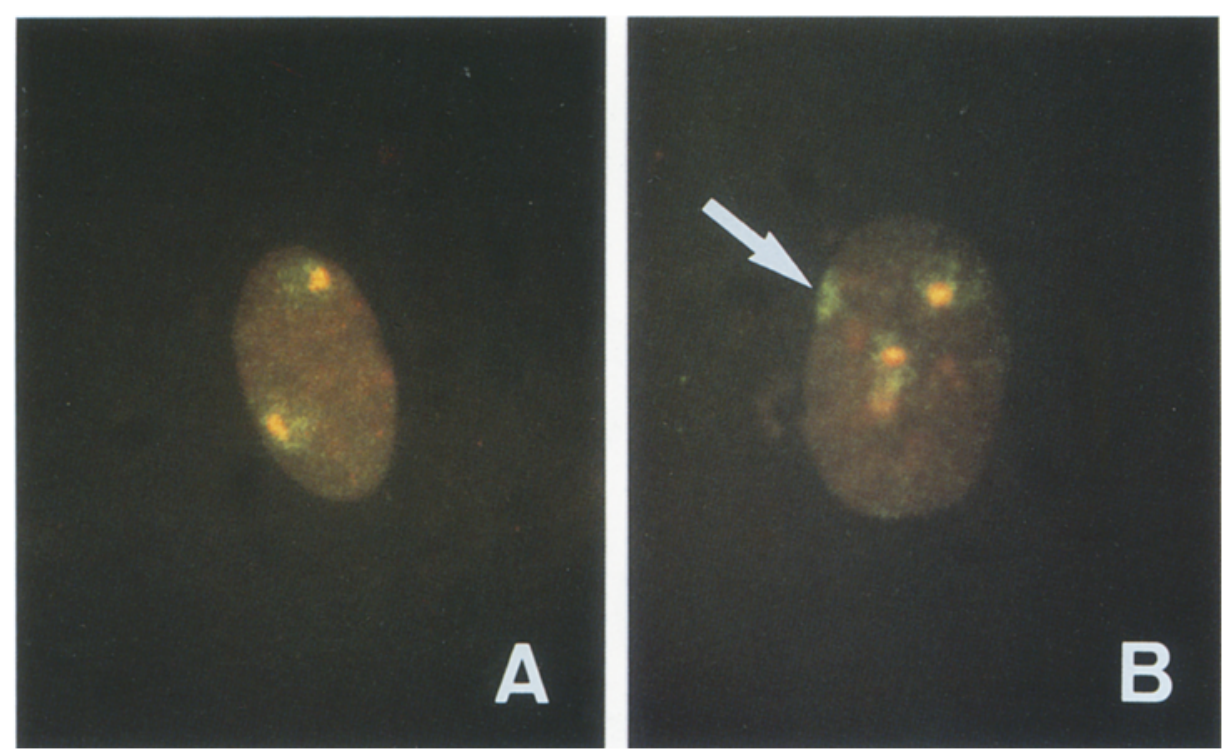

Fig. 2. FISH using digoxigenin-labeled alpha-satellite probe D12Z3 (red) specific for the pericentric region of chromosome 12 , and spectrum green labeled wholechromosome painting probe WCP12 (green) specific for chromosome 12. A: Interphase nucleus with two WCP12 signals and two associated D12Z3 signals indicating disomy for chromosome 12 in a normal cell. B: Interphase nucleus with an extra WCP12 signal (arrow) lacking an associated D12Z3 signal indicating a structural abnormality involving chromosome 12 .

\section{RESULTS}

Of the 50 cultured samples, five showed abnormal karyotypes, 25 showed normal karyotypes, and the remaining 20 were not determined by the conventional cytogenetic method. The nine non-cultured samples could not be karyotyped.

In the control study, the percentage of cultured nuclei showing structural aberrations, numerical aberrations, and a normal pattern of chromosome 12 were $2.1 \%$ (range 1.4 to $2.5 \%$ ), $3.3 \%$ ( 1.4 to $4.8 \%$ ), and $92.7 \%$ (91.0 to $94.9 \%$ ), respectively, and the percentage of non-cultured nuclei were $2.1 \%$ (1.8 and 2.3\%), 1.7\% (1.0 and $2.3 \%$ ), and $94.2 \%(92.4$ and $96.0 \%)$, respectively. In each tumor, when the frequency of signals were statistically different from control groups by chi-square analysis, the tumor was evaluated to have structural or numerical aberrations of chromosome 12 .

The results of FISH analysis for chromosome 12 are summarized in Tables 1 and 2 . Of the 50 cultured samples, 10 showed structural aberrations and four showed numerical aberrations of chromosome 12 . Of the tumors with structural aberrations, tumors 1 and 15 had normal karyotypes, tumors 7 and 40 showed 
Table 1. FISH data for chromosome 12 on cultured cells.

\begin{tabular}{|c|c|c|c|c|c|c|}
\hline \multirow[b]{2}{*}{ Tumor } & \multicolumn{4}{|c|}{ Percentage of interphase cells } & \multirow[b]{2}{*}{ FISH result } & \multirow[b]{2}{*}{ Karyotype } \\
\hline & $\begin{array}{c}\text { Nor- } \\
\text { mal }\end{array}$ & $\begin{array}{c}\text { Structural } \\
\text { abnormality }\end{array}$ & $\begin{array}{l}\text { Numerical } \\
\text { abnormality }\end{array}$ & Others & & \\
\hline I & 67.9 & $21.8^{*}$ & 2.8 & 7.5 & structural abnormality & $46, \mathrm{XX}$ \\
\hline 2 & 91.6 & 1.5 & 2.5 & 4.4 & normal & $\begin{array}{l}46, \mathrm{XX}, \mathrm{t}(1 ; 13) \\
\quad(\mathrm{p} 22 ; \mathrm{q} 34)\end{array}$ \\
\hline 3 & 84.5 & 2.0 & $10.0^{*}$ & 3.5 & numerical abnormality & $46, \mathrm{XX}$ \\
\hline 4 & 91.3 & 2.9 & 2.9 & 2.9 & normal & $46, \mathrm{XX}$ \\
\hline 5 & 93.4 & 2.3 & 2.3 & 2.0 & normal & $46, \mathrm{XX}$ \\
\hline 6 & 86.8 & 2.4 & 3.6 & 7.2 & normal & $46, \mathrm{XX}$ \\
\hline 7 & 54.5 & $37.0^{*}$ & 5.0 & 3.5 & structural abnormality & $\begin{array}{l}\text { 46,XX, dir ins }(4 ; 12) / \\
46, \mathrm{XX}\end{array}$ \\
\hline 8 & 86.0 & 2.0 & 6.5 & 5.5 & normal & ND \\
\hline 9 & 87.6 & 3.3 & 5.3 & 3.8 & normal & ND \\
\hline 10 & 81.5 & 2.2 & $11.0^{*}$ & 5.3 & numerical abnormality & ND \\
\hline 11 & 90.0 & 2.0 & 3.0 & 5.0 & normal & $46, \mathrm{XX}$ \\
\hline 12 & 86.9 & 3.4 & 6.7 & 3.0 & normal & $46, \mathrm{XX}$ \\
\hline 13 & 89.8 & 5.3 & 2.7 & 2.2 & normal & $46, X,-X,+\operatorname{mar}$ \\
\hline 14 & 88.9 & 2.6 & 2.0 & 6.5 & normal & $46, \mathrm{XX}$ \\
\hline 15 & 77.6 & $8.8^{*}$ & 7.6 & 6.0 & structural abnormality & $46, \mathrm{XX}$ \\
\hline 16 & 92.1 & 2.2 & 2.2 & 3.5 & normal & $46, \mathrm{XX}$ \\
\hline 17 & 88.4 & 0.0 & 3.4 & 8.2 & normal & ND \\
\hline 18 & 84.2 & 3.0 & 3.0 & 9.8 & normal & $46, \mathrm{XX}$ \\
\hline 19 & 92.0 & 0.0 & 4.0 & 4.0 & normal & $46, \mathrm{XX}$ \\
\hline 20 & 91.2 & 0.5 & 6.8 & 1.5 & normal & ND \\
\hline 21 & 91.6 & 2.5 & 3.5 & 2.4 & normal & $\begin{array}{l}46, X X, \operatorname{del}(7) \\
(\mathrm{q} 22 \mathrm{q} 32)\end{array}$ \\
\hline 22 & 80.8 & 2.9 & $13.5^{*}$ & 2.8 & numerical abnormality & $46, \mathrm{XX}$ \\
\hline 23 & 87.3 & 3.4 & 3.9 & 5.4 & normal & ND \\
\hline 24 & 88.1 & 0.4 & 6.8 & 4.7 & normal & $46, \mathrm{XX}$ \\
\hline 25 & 87.6 & 2.3 & 4.1 & 6.0 & normal & ND \\
\hline 26 & 90.4 & 0.9 & 2.2 & 6.5 & normal & $46, \mathrm{XX}$ \\
\hline 27 & 88.8 & 0.0 & 5.1 & 6.1 & normal & $46, \mathrm{XX}$ \\
\hline 28 & 87.8 & 1.3 & 4.2 & 6.7 & normal & $46, \mathrm{XX}$ \\
\hline 29 & 90.0 & 1.2 & 5.4 & 3.4 & normal & $46, \mathrm{XX}$ \\
\hline 30 & 90.6 & 2.3 & 2.6 & 4.6 & normal & $46, \mathrm{XX}$ \\
\hline 31 & 90.4 & 1.0 & 5.7 & 2.9 & normal & ND \\
\hline 32 & 87.7 & 1.5 & 4.4 & 6.4 & normal & ND \\
\hline 33 & 66.7 & $26.0^{*}$ & 2.7 & 4.6 & structural abnormality & ND \\
\hline 34 & 87.1 & 1.5 & 4.5 & 6.9 & normal & $46, \mathrm{XX}$ \\
\hline 35 & 82.9 & 1.9 & $9.0^{*}$ & 6.2 & numerical abnormality & $46, \mathrm{XX}$ \\
\hline 36 & 91.5 & 3.5 & 3.0 & 2.0 & normal & $46, \mathrm{XX}$ \\
\hline 37 & 93.5 & 2.0 & 2.0 & 2.5 & normal & $46, \mathrm{XX}$ \\
\hline 38 & 94.3 & 2.4 & 1.4 & 1.9 & normal & $46, \mathrm{XX}$ \\
\hline 39 & 95.3 & 1.7 & 1.7 & 1.3 & normal & $46, \mathrm{XX}$ \\
\hline 40 & 74.6 & $22.4^{*}$ & 2.0 & 1.0 & structural abnormality & $\begin{array}{l}\text { 46,XX, der }(14) \\
\quad t(12 ; 14)(\mathrm{q} 13 ; \mathrm{q} 23)\end{array}$ \\
\hline
\end{tabular}

Vol. 41, No. 1, 1996 
Table 1. (continued)

\begin{tabular}{ccccclll}
\hline \multirow{3}{*}{ Tumor } & \multicolumn{5}{c}{ Percentage of interphase cells } & & \multirow{2}{*}{ Karyotype } \\
\cline { 2 - 5 } & $\begin{array}{c}\text { Nor- } \\
\text { mal }\end{array}$ & $\begin{array}{c}\text { Structural } \\
\text { abnormality }\end{array}$ & $\begin{array}{c}\text { Numerical } \\
\text { abnormality }\end{array}$ & & & & \\
\hline 41 & 85.8 & $11.7^{*}$ & 1.1 & 1.5 & structural abnormality & ND & \\
42 & 47.9 & $47.5^{*}$ & 3.7 & 0.9 & structural abnormality & ND & \\
43 & 49.3 & $47.4^{*}$ & 1.7 & 1.6 & structural abnormality & ND & \\
44 & 48.4 & $49.8^{*}$ & 1.8 & 0.0 & structural abnormality & ND \\
45 & 49.5 & $48.5^{*}$ & 1.5 & 0.5 & structural abnormality & ND \\
46 & 95.8 & 1.4 & 1.4 & 1.4 & normal & ND \\
47 & 91.7 & 2.0 & 2.9 & 3.4 & normal & ND \\
48 & 92.5 & 1.5 & 2.0 & 4.0 & normal & ND \\
49 & 92.7 & 1.3 & 1.3 & 4.7 & normal & ND \\
50 & 93.8 & 2.4 & 1.0 & 2.8 & normal & ND \\
Control & 92.7 & 2.1 & 3.3 & 1.9 & normal & 46,XX \\
\hline
\end{tabular}

ND, not determined.

${ }^{*} \mathrm{p}<0.01$.

structural abnormalities of chromosome 12 by conventional technique, and tumors $33,41,42,43,44$, and 45 could not be karyotyped because of an insufficient number of metaphases. Of tumors with numerical abnormalities affecting chromosome 12 (trisomy 12 or triploidy), tumors 3,22 , and 35 had normal karyotypes by conventional technique, whereas tumor 10 could not be karyotyped because of an insufficient number of metaphases. In the study with non-cultured samples, four showed structural aberrations of chromosome 12, and five showed normal pattern of chromosome 12 by FISH. All of these results were identical to those in the study with cultured samples (Table 2).

\section{DISCUSSION}

Uterine leiomyoma is a benign tumor of smooth muscle that occurs in the female genital organs during sexually mature stage. Although it has been established that ovarian steroids have strong involvement in the development and progress of the tumor (Fujii, 1992; John and Martin, 1971), the details of the mechanisms involved are still largely unknown. Most recent investigators, however, suggest an involvement of chromosomal aberrations in uterine leiomyoma, in particular, aberrations of chromosome 12 (Meloni et al., 1992; Nilbert and Heim, 1990). Nilbert and Heim (1990) have reported that chromosome 12 occupied $39 \%$ of all chromosomal abnormalities. However, there is considerable variation among investigators who have analyzed more than 50 tumors as to the incidence of abnormalities of chromosome 12 in uterine leiomyoma, ranging between 11.1 to 15.0\% (Meloni et al., 1992; Pandis et al., 1991). Much of this wide range in variation is considered due to technical problems associated with banding techniques and culturing techniques. In our study, of 30 tumors which could be 


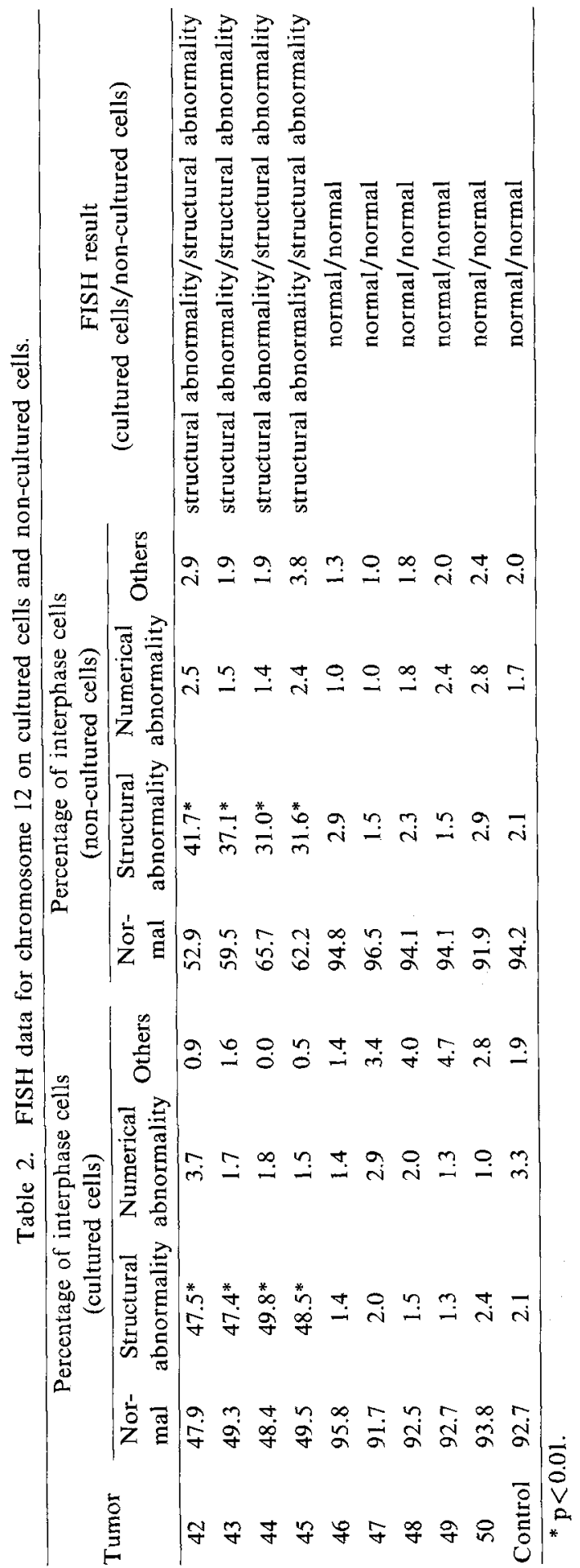

Vol. 41, No. 1, 1996 
analyzed by conventional cytogenetic analysis, two tumors (6.7\%) were found to have an abnormality of chromosome 12 .

For conventional cytogenetic analysis with G-banding, metaphase cells must be obtained and be of sufficient quality. Because metaphase cells constitute only a small proportion of cells present in a cell suspension, the qualitative and quantitative potential of banding techniques is limited. With the development of the FISH technique, it has become possible to analyze chromosomal abnormalities in interphase nuclei. Interphase FISH is a simple and rapid method for detection of specific DNA sequences in the nuclei. Numbers of cells studied can be greatly increased relative to what is analyzed by conventional technique. Clinical utilization of this technique has been useful in malignant hematologic disorders in which cytogenetic analysis provide important information for diagnosis, treatment, and management (Chen et al., 1993; Brizard et al., 1994). FISH is also a powerful tool in the cytogenetic study of solid tumors.

Only a few studies with FISH have reported chromosome abnormalities in uterine leiomyoma. Vanni et al. (1992) described that trisomy 12 was detected by FISH using alpha-satellite probe for chromosome 12. In the present study, we performed FISH study by using combinations of alpha-satellite probes and wholepainting probe for chromosome 12 to detect not only the numerical but also the structural abnormality of chromosome 12. Similarly, Lee et al. (1993) have demonstrated translocation, $\mathrm{t}(\mathrm{X} ; 18)$, in synovial sarcoma by FISH technique. However, FISH results must be evaluated with control study because of overlapping of signals, hybridization failure and artifacts. In the present study, we used cultured and non-cultured uterine myometrium cells as a control.

With FISH, we found chromosome 12 aberrations in two tumors with rearrangements of chromosome 12 identified by conventional cytogenetic method, and in 12 tumors in which we karyotyped as normal by the conventional cytogenetic method or could not be karyotyped. In other neoplasms, similar discrepancies between the results of conventional cytogenetics and FISH have been described by several investigators (Chen et al, 1993; Raghoebier et al, 1992; Lalkin et al., 1993). It is possible that cells with cytogenetic rearrangements of chromosome 12 have lower mitotic rates, and thus are under represented in the metaphase cell populations which are scorable with conventional staining techniques. Overall, the frequency of rearrangements of chromosome 12 detected by FISH and conventional methods in the present study is $28.0 \%$ which is higher than frequencies (range 11.1 to $15.0 \%$ ) detected by other investigators analyzing more than 50 tumors with conventional cytogenetic methods (Meloni et al., 1992; Pandis et al., 1991). Thus the detection of chromosome 12 rearrangements was enhanced with interphase FISH. Problems of culture method in solid tumors is overgrowth by normal (diploid) cells due to a very low mitotic index, particularly in benign tumors, and the length of time required to complete a full conventional cytogenetic analysis. Additionally, the prevailing cells following prolonged cul- 
ture may not necessarily represent the major clone in the tumor in vivo. In the present study, we rapidly detected chromosomal aberration of chromosome 12 in non-cultured samples. The result was identical to those of cultured samples. Our data suggest that interphase FISH analysis using non-cultured cells from uterine leiomyoma may provide rapid and reliable clinical information.

In the present study, by both conventional cytogenetic analysis and FISH, we found $28.0 \%$ (14) of all tumors examined had chromosomal abnormalities of chromosome 12. This suggests the involvement of abnormalities of chromosome 12 in tumorigenesis and progression of uterine leiomyoma. Other cytogenetic studies have also been performed on various benign tumors, such as lipomas and pleomorphic adenoma of salivary gland, in which abnormalities of chromosome 12 were identified (Mark and Dahlenfors, 1986; Nilbert and Heim, 1990; Sreekantaiah et al., 1991; Sreekantaiah and Sandberg, 1991). This specificity suggests that genes important in growth regulation of benign neoplasms are located at these chromosome sites. A breakpoint in structural abnormalities of chromosome 12 in benign tumors has frequently been observed in regions $13-15$ of the long arm. The preferential involvement of 12q13-15 in these benign tumors suggests that alteration of a gene at this locus is associated with tumor development.

In conclusion, our data indicate that chromosomal abnormalities of chromosome 12 are important in the biology of at least some types of uterine leiomyoma. FISH is a sensitive method and a convenient complement to conventional cytogenetic analysis in particularly solid tumors which have technical obstacles to obtaining sufficient quantities of quality metaphases.

Acknowledgments We wish to thank Dr. Robert G. Best for reviewing the manuscript. We also wish to thank Dr. Ueda, Dr. Nomura, and Dr. Teramoto (Department of Obstetrics and Gynecology, Hiroshima Kinen Hospital), and Dr. Urabe and Dr. Mizunoe (Department of Obstetrics and Gynecology, Kenritsu Hiroshima Hospital) for providing tumor samples. This study was supported in part by Grants-in-Aid for Scientific Research from the Ministry of Education, Science and Culture of Japan (No. 06771338, 07671788).

\section{REFERENCES}

Brizard F, Brizard A, Guilhot F, Tanzer J, Berger R (1994): Detection of monosomy 7 and trisomies 8 and 11 in myelodysplastic disorders by interphase fluorescent in situ hybridization. Comparison with acute non-lymphocytic leukemias. Leukemia 8: 1005-1011

Chen Z, Morgan R, Stone JF, Sandberg AA (1993): FISH: a useful technique in the verification of clonality of random chromosome abnormalities. Cancer Genet Cytogenet 66: 73-74

Fujii S (1992): Uterine leiomyoma: pathogenesis and treatment. Acta Obstet Gynaecol Jpn 44: 994-999

John AH, Martin R (1971): Growth of leiomyomata with estrogen-progestogen therapy. J Reprod Med 6: 49-51

Lalkin A, Lishner M, Gaber E, Manor Y, Fejgin M, Ravid M, Amiel A (1993): In situ hybridization: a simple and sensitive method for detection of trisomy 12 in chronic lymphocytic leukemia. Cancer Genet Cytogenet 70: 21-24

Vol. 41, No. 1, 1996 
Lee W, Han K, Harris CP, Shim S, Kim S, Meisner LF (1993): Use of FISH to detect chromosomal translocations and deletions. Am J Pathol 143: 15-19

Limon J, Dal Cin P, Sandberg AA (1986): Application of long-term collagenase disaggregation for the cytogenetic analysis of human solid tumors. Cancer Genet Cytogenet 23: 305-313

Mark J, Dahlenfors R (1986): Cytogenetical observations in 100 human benign pleomorphic adenomas: specificity of the chromosomal aberrations and their relationship to sites of localized oncogenes. Anticancer Res 6: 299-308

Meloni AM, Surti U, Contento AM, Davare J, Sandberg AA (1992): Uterine leiomyomas: cytogenetic and histologic profile. Obstet Gynecol 80: 209-217

Nilbert M, Heim S (1990): Uterine leiomyoma cytogenetics. Genes Chromosomes Cancer 2: 3-13

Pandis N, Heim S, Bardi G, Flodérus UM, Willên H, Mandahl N, Mitelman F (1991): Chromosome analysis of 96 uterine leiomyomas. Cancer Genet Cytogenet 55: 11-18

Raghoebier S, Kibbelaar RE, Kleiverda JK, Kluin-Nelemans JC, van Krieken JHJM, Kok F, Kluin PM (1992): Mosaicism of trisomy 12 in chronic lymphocytic leukemia detected by non-radioactive in situ hybridization. Leukemia 6: 1220-1226

Sreekantaiah C, Leong SPL, Karakousis CP, McGee DL, Rappaport WD, Villar HV, Neal D, Fleming S, Wankel A, Herrington PN, Carmona R, Sandberg AA (1991): Cytogenetic profile of 109 lipomas. Cancer Res 51: 422-433

Sreekantaiah C, Sandberg AA (1991): Clustering of aberrations to specific chromosome regions in benign neoplasms. Int J Cancer 48: 194-198

Vanni R, Van Roy N, Lecca U, Speleman F (1992): Uterine leiomyoma cytogenetics III. Interphase cytogenetic analysis of karyotypically normal uterine leiomyoma excludes possibility of undetected trisomy 12. Cancer Genet Cytogenet 62: 40-42 